infant who acquired hepatitis from her mother. $\mathrm{Br}$ Med $\mathrm{J}$ 1970; iv: 719-21.

3 Bancroft W H, Warkel R L, Talbert A A, Russell P K. Family with hepatitis-associated antigen. JAMA 1971; 217: 1817-20.

4 McCarthy J W. Hepatitis B antigen (HBAg)-positive chronic aggressive hepatitis and cirrhosis in an 8-monthold infant. A case report. J Pediatr 1973; 83: 638-9.

5 Fujiwara T, Abe M, Tachi N, Jo M, Shiroda M. HBsAg-positive infantile hepatitis associated with chronic aggressive hepatitis (in Japanese). Shonika Rinsho 1975; 28: $1303-6$.
6 Yoshida A, Tozawa M, Furukawa N, Oya N, Kusunoki T, Kiyosawa N. HBsAg-positive chronic active hepatitis in a 1 and 1/2 year-old-child (in Japanese). Shonika Shinryo 1977; 40: 1246-50.

Correspondence to $\operatorname{Dr} T$ Shinozaki, Department of Paediatrics, Teikyo University School of Medicine, 11-1 Kaga, 2 Chome, Itabashi-ku, Tokyo 173, Japan.

Received 26 November 1979

\title{
Disseminated eosinophilic infiltration of a newborn infant, with perforation of the terminal ileum and bile duct obstruction
}

\author{
S M MURRAY AND C J WOODS
}

Department of Pathology and Department of Paediatrics, Victoria Hospital, Blackpool

SUMMARY A preterm boy died 4 days after delivery from septicaemia which at necropsy was found to be due to perforation of an eosinophilic lesion of the terminal ileum. Eosinophilic infiltration was also found in kidney, lymph node, bone marrow, portal tracts of liver, gall bladder, and bile duct with associated obstruction of the cystic duct and mucocele of the gall bladder. No allergic cause for the infiltrate was found in either the infant or his mother. Eosinophilic infiltration of neonatal spleen, lymph node, intestinal mucosa, epicardium, thymus, pancreas, portal tracts of the liver, and skin has been reported but the aggressive behaviour of the infiltrate in this patient bears more resemblance to the eosinophilic gastroenteritis that has been described in older children and adults.

Eosinophilic infiltration of the alimentary tract of the adult occurs in two forms-namely eosinophilic gastroenteritis and inflammatory fibroid polyp of the gastrointestinal tract-each has been comprehensively reviewed by Johnstone and Morson. ${ }^{1-2}$ The condition is described much less often in children and in two reviews ${ }^{3-4}$ only 13 cases were recorded in children under 12 years, the youngest being a 2-yearold boy. Eosinophilic infiltration of the gastrointestinal tract has also been described in neonatal necrotising enterocolitis ${ }^{5}$ but the significance of this infiltrate is unknown. No reference to disseminated eosinophilic infiltration in the neonate followed by intestinal perforation has been found in a search of the recent literature.

\section{Case report}

A white boy, weighing $1490 \mathrm{~g}$, was born by spontaneous vertex delivery at 35 weeks' gestation to a healthy 19-year-old rubella-immune group $\mathrm{A} \mathbf{R h}$ positive mother, who had a severe antepartum haemorrhage due to placenta praevia. The pregnancy had been uneventful, apart from vaginal bleeding at 13 and 18 weeks which had settled without treatment on each occasion. No drugs had been taken during the pregnancy.

There was no birth asphyxia, regular respirations were established within 1 minute and, apart from being preterm, there were no abnormalities on clinical examination. 1-mg of vitamin $K_{1}$ was given intramuscularly. Intermittent intragastric tube feeding with low solute milk was started and, apart from occasional regurgitation of small amounts of feed, the infant made satisfactory progress. Meconium was first passed at age 8 hours.

At age $\mathbf{4 8}$ hours the infant's condition deteriorated suddenly with the clinical picture of peripheral circulatory failure. There was no significant abdominal distention. Cerebrospinal fluid showed only 1 lymphocyte $/ \mathrm{mm}^{3}$ and no organisms were found on microscopical examination or culture. The haemoglobin was $10.9 \mathrm{~g} / \mathrm{dl}$, packed cell volume $33.9 \%$, and white blood count $1000 \times 10^{9} / 1$. The scanty nucleated cells seen in the blood film were either lymphocytes or normoblasts with no increase in eosinophils.

Septicaemia was diagnosed and treatment with intravenous gentamicin and cloxacillin was started. 
Oral feeding was stopped and intravenous dextrose saline started. Blood culture subsequently grew Escherichia coli sensitive to gentamicin.

At age 53 hours the infant had a severe apnoeic attack requiring endotracheal intubation and intermittent positive pressure ventilation. $30-\mathrm{ml}$ of blood were transfused and metabolic acidosis corrected with intravenous sodium bicarbonate. However, at age 72 hours abdominal distension developed and the limbs showed sclerematous changes. Refractory hypoxaemia and acidosis ensued and despite continued mechanical ventilation the infant died. He was aged 90 hours.

\section{Necropsy findings}

Perforation of a severely congested short segment of terminal ileum had caused acute peritonitis. The gall bladder was distended with clear mucus and although the common bile duct and hepatic ducts appeared to be patent even a fine probe could not be passed along the cystic duct. The lungs were severely congested. The other organs appeared normal.

Histological examination. The perforated segment of terminal ileum showed intense congestion and oedema with infiltration of the entire thickness of the wall by large numbers of eosinophils together with some lymphocytes and plasma cells (Figs 1 and 2). The serosal surface showed a fibrino-purulent exudate containing, in addition to polymorphonuclear leucocytes, numerous clumps of Gram-negative bacilli and moderate numbers of eosinophils. The gall bladder showed mild focal infiltration of its wall by mononuclear cells and eosinophils while the bile ducts, particularly the cystic duct, showed severe congestion and oedema with cellular infiltration resembling that of the ileum. The liver showed haematopoiesis of normal extent for a preterm infant of this size but eosinophils were absent from these

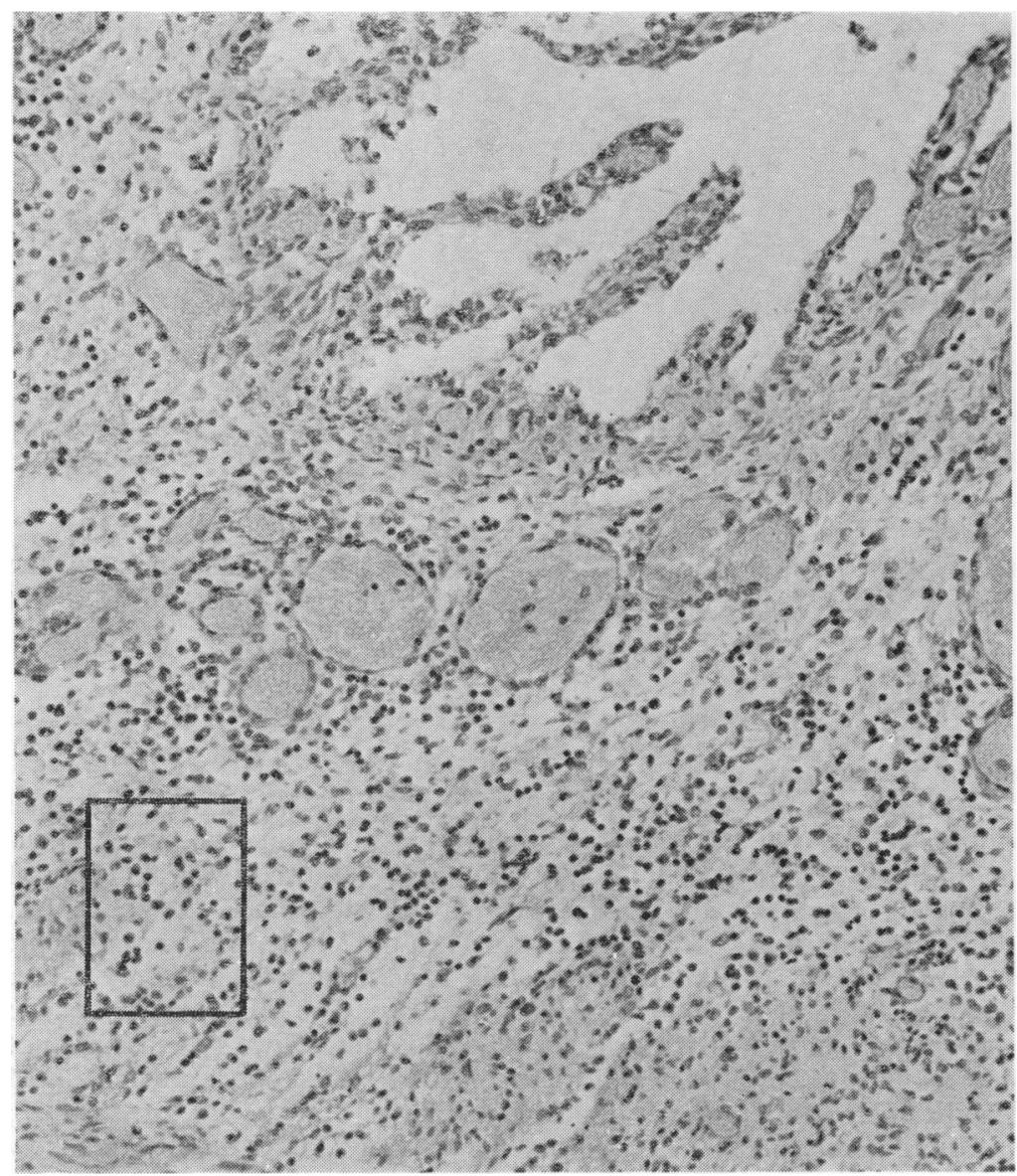

Fig. 1 Full thickness section of terminal ileum near point of perforation showing cellular infiltration. Prominent dilated blood vessels are seen in the submucosa. ( $H$ and $E \times 178)$. 


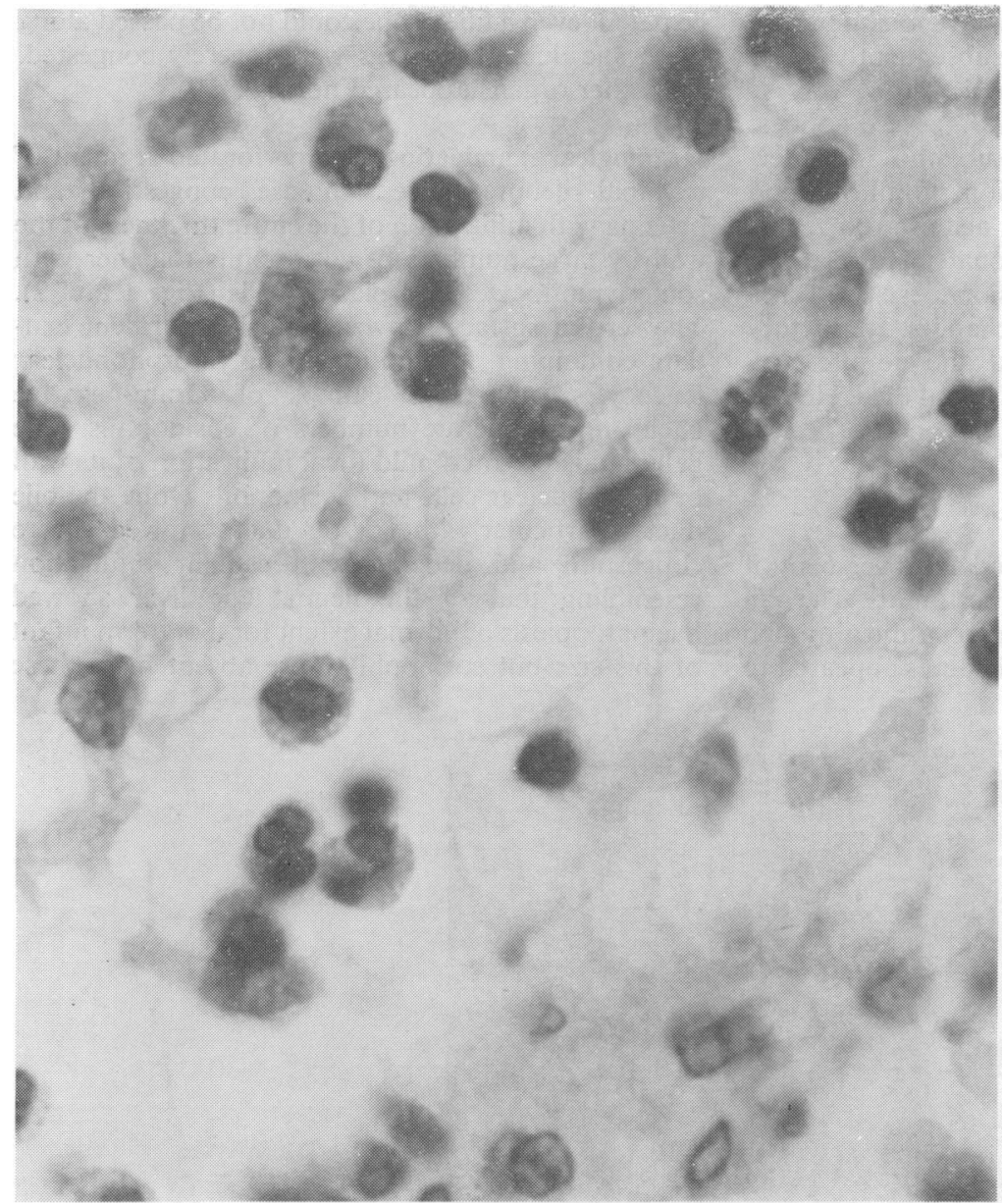

Fig. 2 Greater magnification of boxed area of Fig. $1.49 \%$ of the cells in this field are eosinophils. ( $H$ and $E \times 1650$ ).

haematopoietic foci. The portal tracts contained numerous eosinophils but there was no significant increase in portal fibrous tissue.

The subcapsular region of the kidney showed infiltration by eosinophils which extended deeply into the cortex in a linear manner associated with the nephrogenic formations at the margins of persistent fetal lobules (Figs 3 and 4). The lungs showed intense congestion and intra-alveolar haemorrhage but there was no inflammatory cell infiltration and no eosinophil infiltration. Extra medullary haematopoiesis was not present in the lung. Bone marrow from sternum and upper end of femur was moderately cellular and contained large numbers of mature and immature eosinophils. The subcapsular sinuses of a lymph node from the neck were infiltrated by eosinophils but these were not seen elsewhere in the node. Salivary gland and myocardium appeared normal. In all the tissues except bone marrow the eosinophils were of mature form. Mast cells were not greatly increased in any of the tissues.

\section{Discussion}

The sequence of events in this infant appeared to be eosinophilic infiltration of various organs, particularly the terminal ileum, followed by perforation of the terminal ileum and death from $E$. coli peritonitis. The main interest is in the nature of the eosinophilic infiltrate and this suggests an inflammatory rather than a neoplastic process. The abnormal histiocytic cells characteristic of Letterer Siwe's disease are not seen and the findings do not support a diagnosis of eosinophilic leukaemia.

The infant lived for only 4 days and it is unlikely 


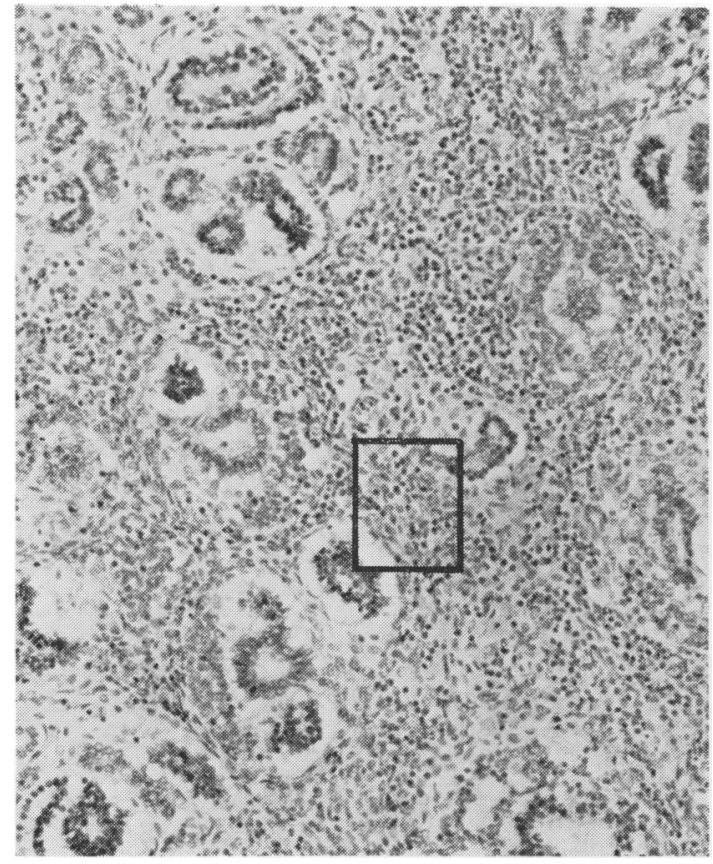

that such a widespread and severe eosinophilia could be an allergic response to the reconstituted milk with which he had been fed for 48 hours before the sudden collapse. The membranes had been ruptured for several hours before delivery but in the absence of inflammatory cell infiltration of the lungs this is an unlikely cause of the abnormal cellular infiltration of other tissues. Careful search of all the fetal tissue taken at necropsy showed no fungi or parasites, or any other causative agents. No eosinophil count was performed on the mother but she had shown no signs of any allergic or other disorder during or after the pregnancy.

A common eosinophilic disorder of the newborn infant is erythema toxicum neonatorum in which the erythematous skin lesions show intense eosinophilic infiltration. 6 Other references to eosinophilic infiltration of the neonate are scanty. Eosinophilic infiltration of the thymus ${ }^{7}$ and portal tracts of the liver $^{8}$ are normal findings in the neonatal period while eosinophils may persist in spleen, lymph nodes, and intestinal mucosa for several months after birth. ${ }^{9}$ Eosinophilic infiltration of the epicardium has been described in 3 infants, 2 of whom had multiple congenital abnormalities, ${ }^{10}$ and Forget
Fig. 3 Renal cortex showing band-like cellular infiltrate at interface between 2 persistent fetal lobules. ( $H$ and $E \times$ 143).

et al. ${ }^{11}$ described eosinophilic infiltration of the oesophagus in a 3-month-old infant. Eosinophilic infiltration of the pancreas in infants born to diabetic mothers is well documented. ${ }^{12}$

Eitzman and Smith $^{13}$ have produced evidence that some infants between ages 2 and 21 days respond to nonspecific stimuli with a pronounced eosinophilia. Perhaps this is the explanation for the widespread eosinophilia seen in our patient and perhaps the initial lesion was necrotising enterocolitis. This view is supported by Tait and Kealy ${ }^{5}$ who stressed the frequent occurrence of eosinophilia in the affected segment of intestine in this form of enterocolitis. However, although necropsy was performed on 1 of their 5 infants, there was no mention of eosinophilia of any organ other than the intestine. In our patient, in addition to eosinophilia of the perforated segment of bowel, there was an increase in eosinophils in the kidney, portal tracts of liver, bone marrow, lymph node sinuses, gall bladder, and cystic duct but not in the lung, salivary gland, myocardium, or blood.

Perhaps this report will draw attention to the possibility that apparently localised eosinophilic lesions in the neonate may in fact be part of a more widespread spectrum of eosinophilic infiltration. 


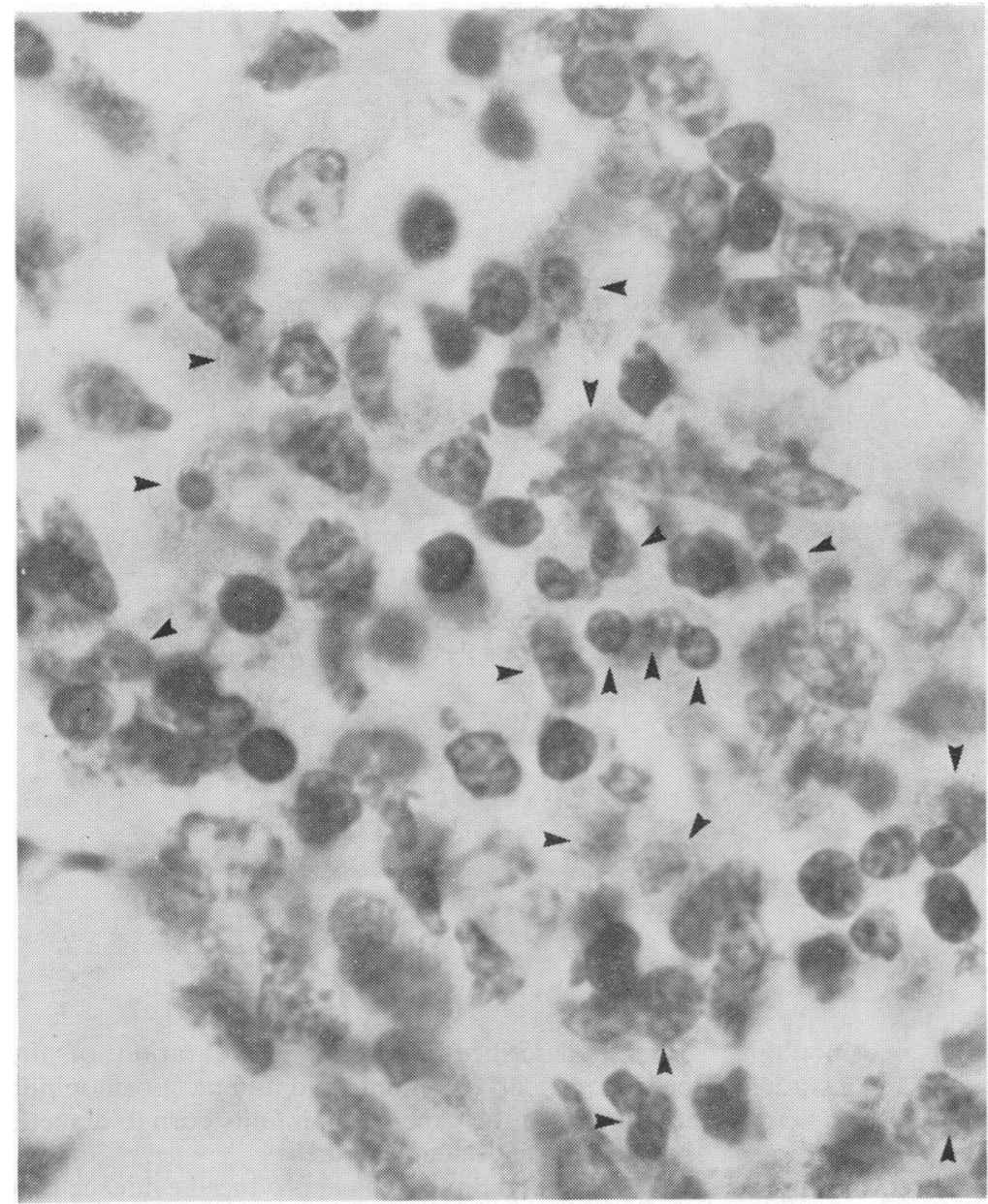

Fig. 4 Greater magnification of boxed area of Fig. 3. Eosinophils are indicated by arrows. ( $H$ and $E \times 1450)$.

\section{References}

1 Johnstone J M, Morson B C. Eosinophilic gastroenteritis. Histopathology 1978; 2: 335-48.

2 Johnstone J M, Morson B C. Inflammatory fibroid polyp of the gastrointestinal tract. Histopathology 1978; 2: 349-61.

3 Jona J Z, Belin R P, Burke J A. Eosinophilic infiltration of the gastrointestinal tract in children. Am J Dis Child 1976; 130: 1136-9.

4 Hoefer R A, Ziegler M M, Koop C E, Schnaufer L. Surgical manifestations of eosinophilic gastroenteritis in the pediatric patient. J Pediatr Surg 1977; 12: 955-62.
5 Tait R A, Kealy W F. Neonatal necrotising enterocolitis. J Clin Pathol 1979; 32: 1090-9.

6 Freeman R G, Spiller R, Knox J M. Histopathology of erythema toxicum neonatorum. Arch Dermatol 1960; 82: 586-9.

7 Bhathal P S, Campbell P E. Eosinophil leucocytes in the child's thymus. Australas Ann Med 1965; 14: 210-3.

8 Potter E L, Craig J M. Pathology of the fetus and the infant. London: Lloyd-Luke, 1976: 395-6.

9 Dourov N. Les eosinophiles tissulaires au cours de la période périnatale humaine. Pathol Eur 1967; 2: 124-45.

10 Moragas A, Vidal M T. Granulomatous eosinophilic 
epicarditis in the newborn. Report of three cases. Arch Pathol 1969 ; 88: 459-62.

11 Forget P, Eggermont E, Marchal G, Geboes K, Jaeken J, Melchior S. Eosinophilic infiltration of the oesophagus in an infant. Acta Paediatr Belg 1978; 31 : 91-3.

12 Pedersen L M, Tygstrup I. Cell infiltration in the pancreas of newborn infants of diabetic mothers. Acta Pathol Microbiol Scand 1968; 73: 537-48.
13 Eitzman D V, Smith R T. The nonspecific inflammatory cycle in the neonatal infant. Am J Dis Child 1959; 97: 326-34.

Correspondence to $\operatorname{Dr} S$ M Murray, Department of Pathology, Victoria Hospital, Blackpool FY3 8NR.

Received 29 January 1980.

\title{
Spontaneous oesophageal rupture with duodenal atresia in a newborn infant
}

\author{
HAJIME NAKAMURA, YOSHIHIKO KANAZAWA, MASAKI HAYANO, AND \\ SHINICHIRO MIMASU
}

Department of Paediatrics, Kobe University School of Medicine, Japan

\begin{abstract}
SUMMARY A newborn infant with spontaneous oesophageal rupture associated with duodenal atresia is described. The diagnosis was established by the pattern of hydropneumothorax on the chest $x$-ray film and by the aspiration of gastric juice by thoracocentesis. Necropsy showed a tear, which extended from the oesophagogastric junction to the upper portion of the stomach.
\end{abstract}

Spontaneous oesophageal rupture in infancy is rare, but it is important to differentiate it from any other disease that causes serious respiratory distress or cyanosis shortly after birth. Since 1952, when the first case of oesophageal rupture was reported, ${ }^{1}$ only 14 cases have been cited. ${ }^{2-3}$ The disease shows a pattern of hydropneumothorax, a finding characteristic on chest $x$-ray films. It should therefore not be too difficult to make an early diagnosis if one knows of the existence of the disease. Some patients survive early surgical operation.

\section{Case report}

A Japanese boy was born after 38 weeks' gestation after induction for hydramnios. Delivery had been spontaneous with a vertex presentation. Birthweight was $2 \cdot 75 \mathrm{~kg}$ and he was the first child of a 26-year-old mother. He cried spontaneously and required no resuscitation. Mucus was suctioned from the nose and nasopharynx, but no tube was passed into the oesophagus. Three hours after birth, breathing was noted to have become laboured and he was placed in an oxygen tent. By 19 hours, the infant was spitting small amounts of bright red blood and the respiration was rapid, shallow, and grunting. He was transferred to this hospital.

On initial examination he was moribund, in severe respiratory distress, with pronounced cyanosis and cold extremities. The abdomen was distended and movement was diminished on the right side of the chest. Petechiae were found on the chest and abdominal walls. Plain $x$-ray film showed tension hydropneumothorax on the right (Figure). In addition, the stomach and duodenum were distended, distal to which no gas was seen. Thoracocentesis was performed; considerable amounts of air and $30 \mathrm{ml}$ of bile-stained fluid were obtained. Respiratory effort was poor and he received assisted ventilation: $\mathrm{pH} 6.98, \mathrm{PaO}_{2} 94 \mathrm{mmHg}(12.5 \mathrm{kPa})$, $\mathrm{PaCO}_{2} 56 \mathrm{mmHg}(7 \cdot 4 \mathrm{kPa})$, base excess $-16 \mathrm{mmol} / 1$. At age 24 hours, a general haemorrhagic tendency and sclerema neonatorum were noted. After exchange transfusion with fresh heparinised blood, the tendency to bleed and the metabolic acidosis, as well as his general condition were improved, but an $x$-ray film showed pneumoperitoneum.

At age 92 hours, laparotomy was performed through an upper midline incision. Purulent matter was attached to the upper portion of lesser curvature of stomach. When the stomach was pulled down, a longitudinal rupture $1.5 \mathrm{~cm}$ in length was found in the anterolateral aspect of the lower end of the oesophagus, spanning the diaphragmatic hiatus and extending to the stomach. The rupture was closed. Atresia of the duodenum was found, the second portion of which ended blindly at an annular pancreas. A duodenojejunostomy was fashioned. A gastrostomy was performed for feeding. The infant tolerated the procedures and chest $x$-ray showed 